\title{
MULHERES RURAIS: GRUPOS PRODUTIVOS E EQUIDADE DE GÊNERO
}

\author{
Vanderleia Alves de Oliveira ${ }^{1}$; Acácia Batista Dias ${ }^{2}$; Ildes Ferreira de Oliveira ${ }^{3}$ \\ 1. Bolsista PIBIC/CNPq, Graduanda em Psicologia, Universidade Estadual de Feira de Santana, e-mail: \\ oliveiraavanderleia@hotmail.com \\ 2. Orientadora, Departamento de Ciências Humanas e Filosofia, Universidade Estadual de Feira de Santana, e-mail: \\ acaciabatistadias02@gmail.com \\ 3. Coordenador do Projeto Ser Tão Forte: Desenvolvimento Territorial Sustentável, Departamento de Ciências Humanas e \\ Filosofia, Universidade Estadual de Feira de Santana, e-mail: ildesferreira@gmail.com
}

PALAVRAS-CHAVE: mulheres rurais; gênero; grupos produtivos.

\section{INTRODUÇÃO}

Este trabalho está vinculado ao Projeto Ser Tão Forte: Desenvolvimento Territorial Sustentável, apoiado pela Chamada Pública CNPq/MDA/SPM-PR No 11/2014 - Núcleos de Extensão em Desenvolvimento Territorial (NEDET). A análise realizada teve como cenário o município de Cícero Dantas, integrante do Território de Identidade Semiárido Nordeste II. A população deste município é de 32.300 habitantes, segundo estimativa da SEI (2012), distribuídos em uma área territorial de $673,00 \mathrm{Km}^{2}$.

O presente estudo consiste no mapeamento de grupos produtivos de mulheres rurais de Cícero Dantas com objetivo de verificar como se organizam e de que forma esse processo contribui em prol da equidade de gênero, uma vez que esta atividade possibilita a essas mulheres inserção no mercado e venda dos seus produtos e a busca por autonomia financeira. A formação dos grupos produtivos potencializa o acesso às políticas públicas específicas para mulheres.

Sabe-se que muitas mulheres atuam na agricultura familiar, entretanto a condição feminina impõe o exercício da dupla jornada, a qual é permeada pela invisibilidade. Siliprandi e Citrão (2011) explanam que as mulheres rurais sempre atuaram na agricultura com seus familiares, mas não tinham seu trabalho reconhecido, este era visto como uma extensão do trabalho doméstico. As poucas oportunidades existentes para as mulheres nos espaços públicos e a baixa inserção delas em programas do governo demonstram a gravidade da situação vivenciada por elas. Entretanto, a partir das lutas contra a discriminação e preconceitos na sociedade, através dos movimentos de mulheres e movimentos feministas, estas passam a ocupar diferentes espaços e ter lentamente suas conquistas, mas ainda não o suficiente para eximir a invisibilidade que perpassa suas atividades produtivas.

É interessante salientar a existência de um não reconhecimento destas atividades, bem como da presença feminina nos espaços políticos. Para Costa (1998), o sujeito político e os movimentos sociais são discutidos de forma assexuada, demonstrando a participação ativa de mulheres, o que colabora para a invisibilidade.

Conforme Costa (1998), quando as mulheres estão engajadas em grupos produtivos e ao conquistarem independência financeira, há uma elevação da autoestima e diminuição do estresse, pois não estão restritas apenas ao âmbito privado e não dependem exclusivamente de seu companheiro. Além do mais, a existência desses grupos é importante, pois coletivamente as mulheres possuem melhores condições de reivindicarem reconhecimento e participação no mercado de trabalho. Outro fator relevante para a visibilidade feminina é a existência e o acesso às políticas e programas sociais, resultado de uma agenda de reivindicações dos movimentos de mulheres. 


\section{MATERIAL E MÉTODOS}

Para realização desta pesquisa foram efetuadas leituras e respectivos fichamentos, necessários para conhecer o tema. Nesse percurso, destacou-se a aproximação com as análises sobre os movimentos de mulheres e suas trajetórias, os obstáculos para a atuação feminina nos espaços públicos, e identificação de programas sociais desenvolvidos para as mulheres e àqueles voltados para as mulheres rurais. Durante o período da pesquisa algumas visitas de campo foram realizadas, a fim de entrevistar integrantes dos grupos produtivos para saber quais os motivos da sua formação, número de integrantes, as ações desenvolvidas, as políticas públicas que o grupo acessa e o impacto do trabalho coletivo na vida das integrantes, uma vez que, a inserção delas no grupo, possibilita a obtenção de uma renda, aumentando assim, as chances dessas mulheres conseguirem certa autonomia.

\section{RESULTADOS E DISCUSSÃO}

A partir do levantamento realizado com o apoio da equipe do Núcleo de Extensão em Desenvolvimento Territorial (NEDET) do Semiárido Nordeste II foi possível observar que é pequeno o número de grupos de mulheres no Território, especificamente no município de Cícero Dantas, e a partir desse levantamento juntamente com as informações obtidas nas entrevistas, é possível inferir que há poucas mulheres engajadas em movimentos sociais.

Três grupos produtivos foram identificados, sendo dois com formação mista e um composto apenas por mulheres, a saber, Associação de Beneficiamento do Caju de Campinas de Castro, Associação dos Agricultores e Agricultores da Limeira e Serra Vermelha e o de Beijuzeiras da Lagoa Seca, respectivamente.

A Associação dos Agricultores da Limeira e Serra Vermelha surgiu em 2014, a partir das demandas da comunidade, pois muitas pessoas produziam hortaliças e necessitavam de uma organização para comercializar seus produtos e também para tentar parcerias e conseguir benefícios que fossem direcionados para trabalhadores/as rurais. A associação é composta por 23 (vinte e três) membros. As mulheres atuam ativamente na associação, mas não em forma de grupo, elas produzem individualmente as hortaliças e comercializam em feiras locais.

A Associação de Beneficiamento de Caju de Campinas de Castro foi fundada em 1999, sendo composta por 20 (vinte) membros do quais 18 (dezoito) são mulheres e dois são homens. O grupo surgiu a partir da ideia de uma pessoa que observou a questão do desperdiço do caju e a viabilidade de aproveitamento desse produto na perspectiva de obter uma renda, essas mulheres abraçaram a ideia e formaram o grupo que logo depois se tornou uma associação.

O Grupo das Beijuzeiras de Lagoa Seca, não se sabe especificamente o ano de fundação, atualmente está inativo. O que foi observado é que há um trabalho em família, onde um membro ajuda o outro nos dias de atividades para a produção de farinha e de beiju. $\mathrm{O}$ relato de uma integrante do grupo revelou a boa intenção da construção do grupo, mas à falta de incentivo do poder público local e de organização das mulheres se constituíram como fatores importantes para o não desenvolvimento do mesmo.

Em relação ao acesso às políticas públicas, os relatos destacam que ocorre de forma sutil, pois falta divulgação, informação e conhecimento da documentação e formas de concorrência aos editais. Entre os programas mais acessados pelas mulheres entrevistadas está o Programa Nacional de Documentação da Trabalhadora Rural (PNDRT), o PRONAFMULHER (Programa de Fortalecimento da Agricultura Familiar), a Declaração de Aptidão ao Pronaf (DAP), o Programa de Fomento às Atividades Produtivas Rurais, Programa Água Para todos, projeto Banco de Semente, Bolsa Família e o Programa Nacional de Florestas (PNF).

Embora se reconheça a importância desses avanços, do ponto de vista da legitimidade social, ainda se observa uma priorização do trabalho masculino em prejuízo ao trabalho feminino, pelo fato de que o homem é considerado o "chefe" da família, especialmente no 
meio rural. Para Faria (2011), as relações patriarcais no campo favorecem a construção de uma visão homogênea da família, na qual as relações de poder estabelecidas priorizam o homem e suas deliberações.

Tendo em vista as desigualdades que perpassam as relações sociais faz-se relevante fazer uso das teorias de gênero, para compreensão das relações entre homens e mulheres, permitindo desnaturalizar noções construídas na divisão de trabalhos entre eles. Para Lisboa e Lusa (2010), lidar com políticas públicas e projetos que tenham por objetivo reduzir as lacunas da equidade de gênero exige que esta perspectiva esteja direcionada para todas as atividades que tenham o desenvolvimento por finalidade.

A partir do trabalho de campo, ouvindo seus depoimentos, observando suas ações, pôde-se constatar que quando estão inseridas em um grupo ativo, as mulheres têm uma mudança de perspectiva em relação ao seu papel na sociedade. Segundo Siliprandi e Cintrão (2011), quando as mulheres rurais fazem parte de grupo de produção e comercialização, há possibilidade não apenas de uma melhoria em sua renda, mas facilita a conquista de sua autonomia econômica, aumento na sociabilidade, visto que agora elas não estão restritas apenas ao espaço doméstico, e observa-se também um aumento da autoestima - o que demonstra a relevância da formação dos grupos. Isso pode ser constatado na narrativa de uma integrante da Associação de Limeira e Serra Vermelha: A partir do momento que eu comecei a vender as hortaliças passei a ter meu próprio dinheiro para comprar as coisas que preciso. (M.J, agricultora).

Quando questionadas sobre a inserção no grupo, as participantes relataram que a iniciativa ocorreu devido à possibilidade de ter um trabalho e obter uma renda. Para uma das integrantes da Associação de Beneficiamento de Caju de Campinas de Castro sua participação, inicialmente, decorreu da possibilidade de crescimento econômico e social e mesmo depois de tornar-se funcionária pública se manteve no grupo para ter uma renda complementar e por ser um espaço que lhe fazia bem: Primeiro, quando o grupo iniciou, eu não tinha nem um trabalho (...) e aí eu vi ali uma possibilidade da gente poder crescer economicamente, assim, em termo de organização social. (J.A, 37 anos, agente comunitária de saúde).

Butto (2011) ressalta que a inserção das mulheres nesses espaços é importante, porque significa que elas estão participando da esfera pública, estão saindo de suas rotinas diárias, essa participação reafirma sua posição como sujeito político e a sua atribuição ganha um novo significado, suas agendas de reivindicação se amplia e questiona-se as desigualdades que lhes são impostas, devido à condição feminina.

Assim, as organizações, principalmente as de mulheres, proporcionam as agricultoras novas perspectivas. Elas relatam positivamente não apenas o desenvolvimento do trabalho e a aquisição de renda, mas a rede de sociabilidade que se cria. Para estas mulheres o momento em que estão trabalhando em grupo vai além do trabalho, é diversão também. Como relata uma das entrevistadas da Associação do Beneficiamento do Caju de Campinas de Castro: Além de melhorar, de ajudar um pouquinho na questão financeira, porque querendo ou não, ajuda, tem também essa importância da gente, do relacionamento com outras pessoas. (J. A, 37 anos). Entretanto, muitas são as dificuldades para adentrarem no espaço público, dentre as quais: a ausência de apoio do poder público, o qual se mostra resistente ao diálogo com elas e a falta de reconhecimento das atividades desempenhadas tanto no âmbito doméstico como na agricultura. Lisboa e Lusa (2010) inferem que há ainda uma indignação com a indiferença do poder público no tocante às famílias que possuem pequenas propriedades, sobretudo, com o reconhecimento e a valorização do protagonismo que as mulheres têm realizado na produção de alimentos e na proteção da biodiversidade. Isso pode ser observado a partir da narrativa de uma entrevistada: Ainda que a gente queira, o poder público não ajuda a gente. A gente formou um Conselho em Cícero Dantas, não deixa a gente trabalhar, o poder público não 
ajuda. (M.A, 66 anos, agricultora). O relato acima revela as dificuldades encontradas para ter apoio e acesso aos órgãos do poder público local.

No entanto, gradativamente as políticas estão avançando nas questões de gênero resultado de pautas de reivindicação e de trajetórias de mobilização, foi com muita luta que as mulheres alcançaram esses espaços que são seus por direito. As mulheres da Associação do Beneficiamento do Caju de Campinas de Castro atestam o acesso às políticas públicas, mas contam com a contribuição da Escola Família Agrícola (EFA) que faz a mediação para que essas políticas cheguem até a elas.

\section{CONSIDERAÇÕES FINAIS}

No processo de pesquisa foi possível observar que as mulheres, ao participarem dos grupos de produção, vislumbram-se mais fortes e com maiores possibilidades de alcançarem seus objetivos. Outros estudos sobre as mulheres rurais do município estudado não foram encontrados, o que atribui um caráter exploratório a esta pesquisa. Ainda é pouco o ingresso das mulheres rurais de Cícero Dantas nas políticas públicas, devido à falta de conhecimento acerca da existência destas políticas e também da dificuldade em cumprir as etapas necessárias para o acesso. O que demanda uma maior atuação do poder público local na mediação destas políticas. A participação feminina nos grupos de produção promove visibilidade das suas atividades e fomenta a participação das mulheres rurais nos espaços públicos.

\section{REFERÊNCIAS}

BUTTO, Andrea et al. Mulheres rurais e autonomia: Formação e articulação para efetivar políticas públicas nos Territórios da Cidadania. Ministério do Desenvolvimento Agrário, Brasília, p.6-114, 2014.

COSTA, Ana Alice A. As Donas no Poder: Mulher e Política na Bahia. Salvador: NEIM/UFBA- Assembleia Legislativa da Bahia. 1998 (Coleção Bahianas; 02)

FARIA, Nalu. Mulheres rurais na economia solidária. In: BUTTO, Andrea et al. Autonomia e cidadania: Políticas de organização produtiva para mulheres no meio rural. Brasília: Ministério do Desenvolvimento Agrário- Mda, 2011. p. 7-192.

Estatísticas dos Municípios Baianos [recurso eletrônico] / Superintendência de Estudos Econômicos e Sociais da Bahia. V.1 (2000). - Salvador: SEI, 2012.

LISBOA, Teresa K, LUSA, Mailiz G. Desenvolvimento Sustentável Com Perspectiva de Gênero-Brasil, México e Cuba: Mulheres Protagonistas no Meio Rural. Estudos Feministas, Florianópolis, p.871-887, set/dez. 2010.

SILIPRANDI, Emma; CINTRÃO, Rosângela. As mulheres Agricultoras no Programa de Aquisição de Alimentos (PAA). Segurança Alimentar e Nutricional, Campinas, v18, n.2, 2011. 